\title{
José Mauro de Vasconcelos: o intérprete e as traduções do Brasil
}

Andréa Borges Leão

\section{Resumo}

Este ensaio aborda a vida e a obra do escritor José Mauro de Vasconcelos e tem o triplo objetivo de discutir comparativamente as lógicas de nacionalização e internacionalização da produção literária juvenil, os deslocamentos e inscrições operados na trajetória do autor e as correspondências entre a sua obra traduzida e os horizontes de expectativa dos leitores brasileiros, franceses e hispano-americanos. As contingências e escolhas no exercício aparentemente desconexo da profissão em José Mauro, intelectual que jamais alcançaria a altura do cânone, dão conta dos polos antagônicos que vão interagindo no espaço literário e orientando a indústria do livro, por todo o século XX: entre passeurs e guardiões das fronteiras nacionais, entre literatura tradicional erudita e literatura estrangeira popular massiva.

Palavras-chave: José Mauro de Vasconcelos; Indústria editorial juvenil; Tradução literária; Literatura popular massiva; Nacional e transnacional popular.

\section{Introdução}

\section{Sentidos e direções da circulação cultural}

No início da década de 1970, a circulação do best-seller O meu pé de laranja lima, entre outros romances de José Mauro, inscreve-se no desenvolvimento da indústria do livro produtora de padróes universais que justificam a exportaçáo mundial da literatura - antes mesmo da telenovela num país de língua portuguesa, periférico e historicamente importador. Os

I Andréa Borges Leão é Doutora em Sociologia e Pesquisadora do CNPq. É professora do Departamento de Ciências Sociais e do Programa de Pós-Graduação em Sociologia da Universidade Federal do Ceará. E-mail: aborgesleao@gmail.com

Direito autoral e licença de uso: Este artigo está licenciado sob uma Licença Creative Commons. Com essa licença você pode compartilhar, adaptar, para qualquer fim, desde que atribua a autoria da obra, forneça um link para a licença, e indicar se foram feitas alterações. 
deslocamentos e inscrições operados na trajetória do autor, tendo em vista as correspondências entre a sua obra traduzida e os horizontes de expectativa dos leitores brasileiros, franceses e hispano-americanos, ${ }^{2}$ acabam por elucidar lógicas de nacionalização e internacionalização da produção literária juvenil. Este artigo situa as reivindicaçóes de independência e autonomia da literatura brasileira no movimento da circulação transnacional da cultura. Tem o propósito de analisar a vida e a obra do escritor José Mauro de Vasconcelos sob o ângulo das trocas e transferências entre nações literárias.

Hoje, em tempos de fusões e de aquisições no mercado editorial globalizado, o best-seller traduzido deixou de ser um problema na literatura para crianças e jovens. A própria ideia da construção de um espaço autônomo de escrita e publicação da ficção nacional, desde finais do século XIX, esteve confrontada à inevitável presença do clássico traduzido, seja como referencial estético assimilado ou rejeitado, objeto de troca intercultural, ou auxílio na constituição de fundos editoriais. Todas essas atribuições foram essenciais para o nascimento da indústria do livro.

Livros vertidos ao transitarem entre espaços nacionais diferenciados e economicamente assimétricos afirmam, acima de tudo, a dimensão universal da literatura. Nos movimentos de transferência, a pretensão de um universal literário se apresenta ao mesmo tempo como estética textual e produto impresso. Por todo o século XX, em que se desenvolve a cultura de massa, os temas e padrôes universais são produzidos pela via do entretenimento, do romance de aventura e do romance sentimental. Para muitos leitores aprendizes, os Contos de fadas de Charles Perrault, de Adensen e os dos irmãos Grimm, o Robson Crusoe e o D. Quixote são as primeiras formas de acesso à cultura impressa, senão ao audiovisual e/ou digital, independentemente da história nacional das obras. Do ponto de vista das práticas de leitura, os critérios de definição dos clássicos universais dependem igualmente das circunstâncias e disposiçóes dos destinatários - as condiçóes variadas de apropriação (CHARTIER, 2014). A existência de referências comuns entre leitores de diversos países e continentes é o que cria o nexo e acaba por eleger as histórias e heróis estrangeiros como preferidos. Assim se passou com $O$ meu pé de laranja lima.

2 Nos limites, abordo apenas a tradução e a recepção da obra do autor no Brasil, França e Argentina. 
A tradução como prática cultural no Brasil tem uma longa história. Wilson Martins (MARTINS, 1979) considera que a publicação de obras estrangeiras vertidas por escritores nacionais assegurou, nas décadas de 1940 e 1950, a consolidação da moderna indústria editorial no Brasil. $\mathrm{O}$ início da tradução como exercício literário, observa José Paulo Paes, remonta ao passado colonial (PAES, 2008). Apesar da forte censura de Portugal, as ideias libertárias dos Enciclopedistas franceses encontraram ecos, por exemplo, em dois corajosos padres carmelitas da Bahia, que verteram do francês $A$ nova Heloísa, de Rousseau. Mas a prática da tradução é uma troca intercultural, lembra ainda Paes, por isso, a importação de livros estrangeiros só se tornará possível com a vinda de D. João VI ao Brasil, em 1808. A fundação da Imprensa Régia, primeira tipografia em território nacional, é aí um marco importante. Só assim, elos entre espaços literários nacionais começariam a ser criados por meio de traduçôes. Estas se destinavam a educar o gosto do rarefeito público leitor, ao mesmo tempo em que profissionalizavam os escritores nacionais em franca concorrência com os tradutores de Portugal. Românticos fluentes em idiomas como Gonçalves de Magalhães, diplomata em Paris, Maciel Monteiro e Caetano Lopes de Moura, complementa Paes (2008), foram convocados por livreiros-editores a se dedicar, amadora ou profissionalmente, a verter romances diretamente das línguas originais de autores já célebres como Victor Hugo, Alexandre Dumar, Walter Scott, Fenimore Cooper e Chateaubriand. Outro marco, cuja importância pode ser medida na longa duração, é a importação do romance folhetim francês como modelo lierário massivo. Sucesso de publicação no rodapé dos jornais antes da edição definitiva em livro, o folhetim traduzido - especialização do escritor Emílio Zaluar - segue a fórmula seriada a ser reutilizada, com enorme aprovação nas novelas de rádio e telenovelas em capítulos, século XX afora.

O caminho trilhado pela Livraria do Globo, de Porto Alegre, oferece uma oportunidade de análise. Funcionando como modelo matricial de conexão entre as práticas de tradução e a consolidação de um mercado editorial no Brasil, as redes de sociabilidade e atuação dos intelectuais na Editora do Globo, situada em espaço periférico, forçaram, a partir dos anos de 1930, as reivindicaçóes de independência e profissionalização da literatura nacional a seguir o fluxo das trocas e empréstimos transnacionais. É o que 
descortina a crônica Um certo Henrique Bertaso do escritor gaúcho Érico Veríssimo $(2011)^{3}$, uma homenagem ao pioneirismo do editor e à história da editora. Desde o início, a linha editorial traçada pela Globo apostou na traduçáo de autores europeus e norte-americanos como estratégia e prática da circulação cultural. Afinal, não seria possível concorrer com a potente José Olympio Editora (SORÁ, 2010), casa do Rio de Janeiro guardiã das fronteiras nacionais que publicava autores de renome, em destaque para os da geração do romance social nordestino, Graciliano Ramos, Rachel de Queiroz, José Américo de Almeida e José Lins do Rego.

Assim e entre outras, foram formadas e difundidas por uma boa rede de distribuição organizada por Henrique Bertaso, desde Porto Alegre, as Coleçóes Amarela, que apresentou Agatha Christie e o gênero policial ao leitor médio; a Globo, formada por livros de bolso de Puchkin, Stevenson, Tchékhov; a Nobel, que apresentou Thomas Mann e Joseph Conrad; e a Coleçáo Nanquinote, que reunia livros ilustrados de grandes formatos dedicados ao público de crianças, como a obra no gênero do próprio Érico Veríssimo. A ilha do tesouro, clássico de R. L. Stevenson, Alice no pais das maravilhas e Através do espelho, de Lewis Carroll, formavam uma unidade junto a Aventuras do avião vermelho (1936) e Aventuras de Tibicuera (1937), na boa safra do autor.

Atuando no seu tempo, a dupla Verríssimo/Bertaso, somado a um time de tradutores que incluía Augusto Meyer, Mário Quintana e Maurício Rosenblatt, e a um agente em Nova Iorque, consolidou um fundo editorial reconhecido por todo o País com base na publicação de escritores regionais e obras traduzidas, que se revestiam de legitimidade pelas versóes dos próprios escritores da casa. E tudo isso obteve um alcance popular massivo. Afinal, com o "olhar maior que o estômago", a dupla sabia do que se passava no mercado mundial das letras: “(...) quero dizer, comprávamos mais direitos sobre livros estrangeiros do que nossa capacidade de editar permitia”. Para tamanha aposta, a Livraria do Globo tornava-se mantenedora do departamento editorial, autorizando os pagamentos da compra de direitos e dos salários dos colaboradores. Nas palavras do orientador literário da casa:

3 Este livro foi publicado em 1972 pela Editora do Globo. A edição referida neste ensaio é a da Companhia das Letras, de 2011 . 
A base do monumento que sustenta as grandes figuras da literatura mundial, como Tomas Mann, Dostoiévski, Wasserman e os autores acima mencionados é feita de uma argamassa popularesca em que aparecem histórias policiais, romances de amor água com açúcar e novelas de capa e espada. (VERÍSSIMO, 201 I, p. 61).

Como observa Elisabeth Torresini, a indústria do livro no Brasil tem a sua especificidade e, por que não, certa dinâmica histórica de direçôes e sentidos (TORRESSINI, 1999). A mesma direção alternativa de circulação da periferia para o centro - agora não mais entre regióes, mas de um país importador para os exportadores de cultura - foi trilhada pela produção juvenil de José Mauro de Vasconcelos, intérprete e tradutor do Brasil. O meu pé de laranja lima, Vamos aquecer o sol e Rosinha, minha canoa exigiram de seu criador uma divisão da autoria literária com editores, tradutores e milhares de leitores espalhados pelo mundo. As disposiçóes desses mediadores em ultrapassar fronteiras e mover-se em diversos sentidos resultaram em vastas redes de interdependência que reposicionaram a literatura brasileira no exterior, criando uma nova comunidade de leitura. As palavras de Veríssimo sobre a autoimagem dos que na Globo dos anos 1940 se lançavam na disputa desigual por autores consagrados no Rio de Janeiro, capital das letras brasileiras, sintetiza a disposição dos artífices da circulação invertida. Uma disposição adquirida no comércio e cujo efeito foi o de inscrever os nossos impressos na história das trocas culturais. Confrontados à "vida de província" não sucumbiriam à imobilidade ou autoimpedimento na conquista de mercado nacional ou transnacional. Importava entreter e oferecer boa literatura ao grande público:

Mas eram escritores da Corte! Apareciam na capital do país. Tinham, além do seu valor próprio indiscutível, boa imprensa. Nós estávamos na Província não só geográfica como também - tínhamos de reconhecer - psicologicamente. Enquanto conversávamos sobre esses problemas eu pensava, melancólico no livro em que estava trabalhando, apenas aos sábados à tarde, já que nos outros dias eu tinha de dedicar dez horas à Revista e às traduções. (VERÍSSIMO, 201 I, p. 37).

\section{Tradução: as versões do gosto}

Com olhos maiores que o estômago - leia-se, a oferta antecipando a demanda -, a importaçáo da literatura de entretenimento estabelecia ordens temáticas duradouras com repertórios textuais aparentemente 
desconexos. Uma rápida sinopse desse processo evocaria ainda as difusóes dos livros europeus pela Livraria Garnier, as adaptaçóes da Livraria Quaresma nos gêneros populares, com destaque para as versóes de Figueiredo Pimentel dos Contos de fada, e as traduçóes de Carlos Jansen das Mil e uma noites, no Rio de Janeiro oitocentista; as inovaçóes e adaptaçóes de Monteiro Lobato para a Editora Nacional, a exemplo das coleçôes Terramarear e Paratodos, e as coleçóes da Editora Melhoramentos, na São Paulo dos anos 1920 e 1930; ou as coleçóes de livros de bolso da Gráfica Tecnoprint/ Ediouro, no Rio de Janeiro de 1960 (LEÃO, 2016).

$\mathrm{Na}$ produção literária para crianças e jovens, as coisas começam a mudar em direção à massificação e, posteriormente, à exportação do livro produzido no Brasil com o aparecimento da figura do diretor de coleção. O primeiro deles foi o diretor da Escola Normal de São Paulo, Arnaldo de Oliveira Barreto, que em 1915 dá início a uma Biblioteca Infantil na Editora Melhoramentos. Reunir títulos em uma coleção para o grande público requer disciplina, contratação de pessoal especializado e planejamento de longo prazo. A Companhia Melhoramentos iniciou suas atividades na fabricação de papel em 1890, nos informa Laurence Hallewell (HALLEWELL, 2012), sob a direção de Antônio Prosst Rodovalho ${ }^{4}$. Somente no final dos anos 1910, complementa Gabriela Pellegrino Soares (SOARES, 2007), inicia suas atividades de gráfica e edição. Em 1915, o imigrante alemão Alfried Weiszflog, um dos fundadores da empresa gráfica Weiszflog Irmãos, aceitando a sugestão do professor Barreto a seu irmáo Walther, passa a produzir material escolar e a imprimir livros de outros editores, como os da Livraria Francisco Alves. Nessas condiçóes é publicado o primeiro volume da Biblioteca Infantil, a tradução de $O$ patinho feio, de Hans Christian Andersen, com ilustraçóes coloridas de Franz Richter. Em abril de 1920, os Weiszflog compram a fábrica de papel Melhoramentos e incorporam a gráfica-editora, passando a produzir, a editar e a comercializar apenas seus livros, e com papel próprio.

Maria das Dores Soares Maziero (MAZIERO, 2015) chama a atenção para a vocação escolar do projeto da Biblioteca Infantil de Arnaldo de

4 Para saber mais sobre a história da Editora Melhoramentos, ver sua página na Internet. Acesso em 23 nov. 2017. 
Oliveira Barreto. O professor exigia no contrato de edição o compromisso da editora na divulgação dos volumes da coleção nas escolas de São Paulo e de outras cidades do país. A partir de 1926 e, de acordo com Gabriela Pellegrino Soares (SOARES, 2006), mais intensamente a partir de 1937, o educador Lourenço Filho promove uma revisão completa nos volumes publicados, objetivando a simplificação do vocabulário, já numa primeira iniciativa de classificação etária, com base nos estudos de psicologia do comportamento e processos de aprendizagem. No total, a coleção alcança, em 1958, 100 títulos. É interessante notar o convívio entre traduções e adaptaçóes de títulos que se reivindicam nacionais, como Saudade, A filha da floresta e Campo e cidade, só para citar a obra de Tales de Andrade. Se um moderno editor precisa estar bastante integrado a economia de seu tempo, como lembra Jean-Yves Mollier (MOLLIER, 2006), tanto mais deve estar conectado aos princípios de educação em voga. Tudo indica que, baseado na psicologia ativa e no papel de transmissáo da literatura como formadora integral do homem, a figura tutelar de Lourenço Filho, a partir do legado de Arnaldo de Oliveira Barreto, preparou um universo de representação para o livro juvenil brasileiro. Como atesta Soares (SOARES, 2006), uma linha educacional e psicológica trazida pelo educador baseada na autonomia da criança para a boa socialização articulava-se a "concepçôes literárias, estéticas e educacionais", pautando um sistema de leitura e avaliação dos livros que a Editora Melhoramentos estudava publicar. Esta orientaçáo vigorou até o ano da morte de Lourenço Filho, em 1970. O meu pé de laranja lima aparece, então, sob esse horizonte editorial e, vale lembrar que, um ano depois, em 1969, a Melhoramentos publica O Sobradinho dos pardais, do escritor baiano Herberto Sales, narrativa sentimental no mesmo estilo, que dá a palavra a um casal de pardais, mas não alcançaria o sucesso de público do livro de José Mauro.

Best e long-seller, há 50 anos $O$ meu pé de laranja lima permanece no catálogo da editora ao mesmo tempo em que rende comercialmente. No volume comemorativo, publicado em 2017, Luiz Antônio de Aguiar informa que desde o seu lançamento o livro vendeu mais de dois milhóes de exemplares só no Brasil e inúmeras ediçóes na Alemanha, Argentina, Áustria, Estados Unidos, Holanda, Inglaterra, Itália, França e em outros países (AGUIAR, 2017). Até o final da década de 1970, de acordo com 
matéria publicada no suplemento Livro do Jornal do Brasil, em 30 de janeiro de 1971, já haviam sido impressos 550 mil exemplares em espanhol, 250 mil em japonês, 160 mil em alemão, 85 mil em francês e $60 \mathrm{mil} \mathrm{em}$ inglês, entre outras línguas. $\mathrm{O}$ romance também foi comemorado pela sua contemplação por três vezes com o prêmio francês Le Monde Chrétien, indicado por editores, livreiros, críticos, "um rabino, um pastor protestante e um padre católico". Esta matéria se intitulava Nunca se editou tanto no país e jamais se leu como agora e tinha como objetivo divulgar o resultado de uma pesquisa sobre o crescimento da produção editorial e gráfica brasileira realizada pela Fundação Getúlio Vargas e financiada pelo Grupo Executivo da Indústria do Livro (GEIL) e Banco Nacional de Desenvolvimento Econômico (BNDE). Com um levantamento de 160 editoras, 87 gráficas e 116 livrarias, noticiava a abertura de 20 novas editoras a cada mês, de parques gráficos, assim como o enfrentamento dos problemas de distribuição e comercialização. A matéria concluía pela evidência do aumento do volume de vendas. Esses números dizem muito a propósito dos ventos de mudança que sopravam a favor da consolidação de uma moderna indústria do livro. Note-se que o momento era de expansão de um sistema de comunicação de massa, recolocando a questão do nacional/estrangeiro fora do par dependência/colonialismo. Felipe Lindoso (2015), a partir de dados disponibilizados pela base Index Translationum, da UNESCO, chama a atençáo que mesmo com o passar dos anos, em 2015, a obra de José Mauro ainda constava como a oitava mais traduzida no mundo entre autores de língua portuguesa, ficando atrás apenas de Paulo Coelho, José Saramago, Jorge Amado, Fernando Pessoa, Leonardo Boff, Eça de Queiroz e Lobo Antunes. Tudo indicando, nas palavras de Renato Ortiz, que "(...) a busca de uma identidade nacional se insere na trama da história brasileira na sua relação com o mundo exterior" (ORTIZ, 1994, p. 183).

$\mathrm{Na}$ produção da indústria cultural brasileira uma cultura popular de massa já estabilizara, desde a década de 1940 com a influência das radionovelas latino-americanas e da fotonovela italiana, um mercado em boa parte produtor de sentimentalismos e de aventuras voltados para o público feminino, obseva Ortiz (ORTIZ, 1994). No entanto, um caminho alternativo para se pensar a indústria da cultura e, em consequência, a base transnacional da cultura de massa, é oferecido por Jean-Yves Mollier (2006) nos 
estudos sobre a circulação dos impressos e livros. Argumenta o historiador que essa forma de cultura teria como propriedade distintiva a produção seriada de produtos padronizados, em geral, para serem consumidos fora das fronteiras nacionais. Decorrem desta linha de argumentação interpretaçóes catastróficas de seus usos e efeitos, sobretudo da parte dos que se encarregavam em compreendê-la no modelo dos Estados Unidos do pós-Segunda Guerra. Theodor Adorno e Max Horkheimer inauguram essa posição que, aliás, foi ainda mais radicalizada por Umberto Eco. Ampliando a cronologia de todo o processo da comunicação de massa, Mollier desloca para a França do final do século XIX e início do século XX o advento de uma estrutura de difusão ampliada alicerçada na edição de livros escolares, de mapas e coleçôes de bolso, literatura juvenil, quadrinhos e romances sentimentais, entre outros gêneros que juntos formavam uma cultura midiática. Isto se deveu a uma reforma educacional exitosa e ao desenvolvimento de uma imprensa e edição de vocação exportadora, antes mesmo da generalização do rádio, da televisão e da internet. Não por acaso, os livreiros franceses radicados no Rio de Janeiro, no meado do século XIX, destacaram-se na importação e comércio do que se tornaria um repertório popular massivo. Mais tarde, os clássicos traduzidos se espalhariam para bancas de jornais e outros pontos de venda do País, organizando acervos de coleçôes e séries nos catálogos dos modernos editores.

O movimento de unificação das lógicas nacional e internacional produzia, sobretudo, a direção inversa da circulação literária. Sem equivalências possíveis, uma vez que a concorrência nas trocas entre naçóes centrais e periféricas é sempre desigual, o livro juvenil produzido no Brasil também entrava em coleçóes organizadas por editoras de outros países. E, na condição de gênero nobre produtor de universais na indústria cultural, a partir da década de 1970, as práticas de tradução de livros como $O$ meu pé de laranja lima junto aos romances de Jorge Amado e Érico Veríssimo Dona flor e seus dois maridos, Gabriela cravo e canela e Clarissa, só para citar os mais lidos - davam banhos de popularidade em outros escritores sul-americanos nas feiras internacionais, reposicionando a literatura brasileira na circulação transnacional da cultura. No âmbito hispano-americano, a trajetória de Haydée Mercedes Jofre Barroso, jornalista e figura ímpar de passeur - leitora, crítica e tradutora - tem muito a dizer sobre a inversão 
da circulação literária do Brasil para a Argentina e Espanha. Seu projeto de tradução conferiu a Vasconcelos prestígio e reconhecimento, sem contudo tomá-lo por uma figura de intelectual inovador na forma ou que encarnasse um momento forte de reivindicação nas lutas de autonomia da produção cultural brasileira.

$\mathrm{Na}$ monografia que consagrou ao escritor, Vida y saga de José Mauro de Vasconcelos, publicado pela El Ateneo Editorial, de Buenos Aires, a casa do autor em língua espanhola, Haydée conta que num belo dia de fins dos anos 1970, o editor Pedro García presenteou-a com um exemplar de O meu pé de laranja lima e em seguida solicitou a sua opiniáo “(...) sobre las posibilidades que la dicha novela podría tener en el mercado de habla castellana" (BARROSO, 1978). Já o tendo lido e apreciado em português e, sobretudo, já sabendo que a obra do autor era conhecida na Europa, a opinião de Barroso foi absolutamente entusiasmada. $\mathrm{O}$ passo seguinte seria a contratação dos direitos de tradução do texto com a Editora Melhoramentos. Nesse ínterim, Haydée inicia uma amizade epistolar com o autor. Prometeu-lhe manter-se fiel à simplicidade coloquial de um estilo que a encantava, “(...) y haberle satisfecho en la misma medida en que él me satisfizo a mi com su bellísima historia: por lo menos así nos lo hemos dicho mutuamente - ya tenía otro idioma que cambiaba de nombre pero no de esencia a sus palabras" (BARROSO, 1978). Assim, conheceu a luz da publicidade Mi planta de naranja-lima e, do mesmo modo, o nome do brasileiro incluía-se na história literária argentina.

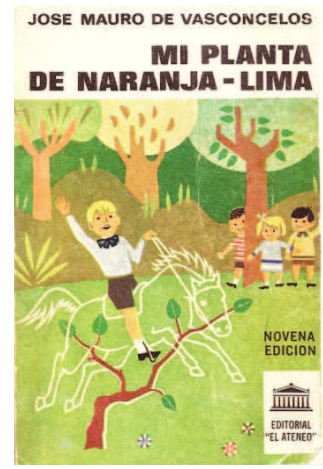

Figura I - Capa de Mi planta de naranja-lima 
Para Gustavo Sorá (2003), a figura de intermediária de Haydée Barroso representa um ponto de mutação entre a velha crítica erudita e um novo modelo praticado por carreiras intelectuais que se firmavam no jornalismo e na universidade. Neta de proprietários de terras no Brasil e tendo aprendido o português em família, contou com a ajuda da tia, Zelma Barroso de Oliveira, que havia sido Cônsul do Brasil na Argentina, para estudar Letras e Jornalismo na Universidade do Rio de Janeiro, por cinco anos. No regresso a Buenos Aires, continua Sorá, no meado dos anos 1960, “ (...) traía el reconocimiento del Premio Simón Bolívar, que otorgaba el Comité de Intercambio Cultural Panamericano, y los originales de um libro que en su título manifestaba el proyecto autoral de Haydée Barroso: Esquema histórico de la literatura brasileña" (SORÁ, 2003, p. 181). Trabalhando como funcionária do Setor Cultural da Embaixada do Brasil em Buenos Aires, consolida seu percurso crítico-autoral vertendo para o espanhol Jorge Amado e publicando uma biografia de Monteiro Lobato, antes do ensaio que sairia, em 1978, sobre José Mauro de Vasconcelos. O posto na Embaixada lhe possibilitou inúmeras viagens ao Brasil, França, Portugal, Itália e Estados Unidos, além da promoção de importantes coediçôes, como as que apareceram pela Sudamericana (SORÁ, 2003). Juntar o seu nome ao de Vasconcelos conferiu-lhe renome como tradutora, conclui o sociólogo, sobretudo pelo trabalho de apresentação dos livros do escritor nas escolas. Assim, apresenta suas razóes razóes e justifica a aposta no interesse do público em idioma espanhol:

Comencé mi amistad literaria com Vasconcelos en 1970, cuando después de haber finalizado la lectura de uno de sus libros decidi ocuparme periodísticamente de esse escritor que era un poco el fenómeno literario del Brasil en esos momentos; esa lectura había constituido un casi deslumbramiento - casi, poque a los críticos, después de algunos años de actividad, si a ella unimos los años de formación universitaria, a veces la docencia y siempre la lectura apasionada y apasionante, ya pocas cosas pueden deslumbrarnos ... -, en todo caso, un puente de emoción entre el autor y yo. El diálogo estaba entablado. Ahora había que caminar hacia la amistad, y yo me encontraba preparada para ello. (BARROSO, 1978, p. 9).

Se as práticas de tradução expressam versôes do gosto e produzem efeitos de legitimação para obras e autores em espaços de referências culturais diferenciadas, a ponte de emoção e amizade construída entre José Mauro e Merceditas - o escritor a tratava pelo segundo prenome - visava a realçar 
a humanidade construída nas histórias de crianças pobres trabalhadoras da América Latina e nas sagas de índios sul-americanos da selva amazônica. Talvez o pacto do jovem leitor argentino com o escritor brasileiro que se autorrepresentava mestiço, filho de pai português e mãe indígena, permitisse uma projeção dos heróis fora da escrita, uma projeção no mundo de identificações do consumo cultural. Esse mundo produzia entretenimento com matéria exótica, tirando o máximo proveito dos tropismos exercidos pelo Brasil. A força expressiva do caboclo Zé Orocó, personagem que enlouquece em Rosinha, minha canoa (1963), ecoaria na narrativa confessional de Zezé, no tempo de infância que passa pela travessura e pela dor em $O$ meu pé de laranja lima. Ambos os heróis arrancavam lágrimas e davam ao leitor estrangeiro a impressão de familiaridade ao antropomorfizar elementos da natureza tropical despercebidos aos que viviam na civilizaçáo das grandes cidades. Desse modo, a ternura que emanava dos dois Zé, o adulto e a criança, quando falavam com uma canoa de madeira e uma árvore, tocava a sensibilidade do público de todas as classes e idades. No mundo de diversão e curiosidade criado pela indústria do livro, o encontro com as emoçóes infantis se convertia no encontro de descoberta e conhecimento da alteridade tropical, aproximando itinerários civilizatórios, como pensava Norbert Elias (ELIAS, 2011).

Posto por ela em língua espanhola, Haydée Barroso comparava Vasconcelos ao francês Saint-Exupéry, Mi planta de naranja-lima ao Principito. Restava ao leitor aguardar um pouco, logo o livro aparecido em Buenos Aires em 1971 e já popular em Paris, entraria no cinema, trilhando o caminho da indústria da cultura.

Nadie busque en este libro - cuyo protagonista apenas tiene cinco años - aventuras emocionantes ni raras sensaciones; se trata de una obra clara y límpida, hecha com amor y nostalgia, en un estilo fluido y simples. Búsquese, sí, la poesia, el lirismo y la ternura que chorrean como miel desde cada página, la habilidad de un escritor para revestir de poesía las cosas más triviales. (BARROSO, 1978, p. 10).

Ademais, havia o problema da construção ficcional do índio sul-americano tendo por base valores universais, tópico explorado no ensaio crítico de Barroso. Os especialistas Syria Poletti e Samuel Tarnopolsky são convocados por ela para comentar os temas em destaque na obra de José 
Mauro. A primeira, uma professora, tradutora e premiada escritora de literatura para crianças, o enquadra na atualidade de um realismo poético. José Mauro, como os clássicos europeus, seria o enlace que faltava na Argentina. Uma infância pobre enriquecida de sensibilidade e humanidade construída na sua obra o aproximaria de Dickens ou Andersen, continua Poletti, e, por isso, satisfazia e adaptava-se ao gosto de leitores de várias faixas etárias. Ou melhor, "Vasconcelos posee una magnética capacidad de comunicación” (BARROSO, 1978, p. 71). O que significa afirmar que os princípios transmitidos por suas histórias pouco representariam se a experiência do escritor não possibilitasse conhecer suas aplicaçóes na vida do leitor. Haydée Barroso chama atenção, em várias passagens, sobre os nexos entre a limpidez da linguagem, a eleição dos temas e a experiência de juventude do autor na selva amazônica. Ao lado dos irmáos Villas-Bôas, José Mauro desbravou a regiáo do Araguaia, afetuosamente transmutada em sua ficcção. Assim, pensava criticamente Syria Poletti; "Vasconcelos nos da una creación estética sustentada en valores universales, dentro de una estructura formal que refleja el ámbito histórico y geográfico en el que está inmerso". Samuel Tarnopolsky, por sua vez, destaca a forte veia indigenista do escritor brasileiro. Olhando-o comparativamente, a diferença de Vasconcelos com relação aos colegas do país vizinho estaria no manejo das emoçóes, na ternura com que revestia seus cenários e personagens, além da presença de crianças índígenas nas tramas. Ou melhor, situando-o na lógica da produção literária de univesais, Tarnopolsky enfatiza: “ (...) en nuestra literatura, el indio nunca se desprende de su condición diferenciada. En Vasconcelos bastaría no poner el nombre o las palabras de su proprio idioma para que no advirtiéramos su especificidad étnica: es igual a nosotros, culto o inculto, vestido o desnudo" (BARROSO, 1978, p.76).

Por exemplo, o mesmo não poderia ter se passado com a selva recriada ficcionalmente nos contos do escritor uruguaio Horácio Quiroga, chamado por Monteiro Lobato o Rudyard Kipling das Américas. Gabriela Pellegrino Soares (SOARES, 2007, p. 112), chama a atenção, em Quiroga, para a dimensão pitoresca e divertida da vida na selva das missóes argentinas, para as alianças e embates entre os homens e os animais, com "recursos e formas de expressões regionais”. Sem a dimensão trágica e densidade psicológica de José Mauro de Vasconcelos, Quiroga escreveu Cuentos de 
la selva para niños, em 1917, com o intuito de divertir seus filhos e com olhos postos no universo escolar onde o livro seria adotado, complementa Soares. 5 Em se tratando de matrizes de culturas diferentes é interessante observar de que modo cada uma delas, a francesa e a argentina, conceitua a aventura e o exótico na obra literária. É especialmente interessante indagar o funcionamento na longa duração do imaginário francês sobre o Brasil, seja na literatura de viagem dos cientistas, comerciantes e aventureiros que produziram relatos sobre o Brasil no século $\mathrm{XIX}^{6}$, seja por via dos tradutores literários na função de intermediários especializados da circulação cultural. Há algo que não se deve perder de vista: cada edição nacional pôde colocar $O$ meu pé de laranja lima em um gênero determinado. $\mathrm{Ou}$ melhor, a sua indicação "infantojuvenil” fez parte de um jogo de critérios historicamente modificados na configuração formada pelo autor, os editores e tradutores, a crítica e os leitores. Assim como na Argentina, na França o livro de José Mauro foi recebido pela estetização de uma pedagogia sentimental articulada ao critério do entretenimento, o que atesta a opiniáo de Nières-Chevrel de que os empréstimos são, sobretudo, entre conceitos editoriais (NIÈRES-CHEVREL, 2008).

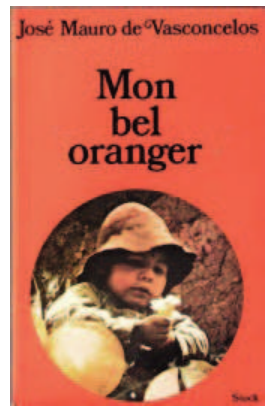

Figura 2 - Capa de Mon bel Orange

5 O estudo comparado entre as obras traduzidas e trajetórias de José Mauro de Vasconcelos. Horácio Quiroga e Rudyard Kipling, o que poderia haver em comum no plano das gerações literárias, fica para uma próxima ocasião.

6 A respeito da história do imaginário francês sobre o Brasil, a partir da literatura de viagem como fonte documental, o melhor a consultar é o liuro de Regis Tettamanzi, Les écrivains français et le Brésil. 
No dia 17 de novembro de 1971 é publicado na Bibliographie de la France, o Journal Général de l'Imprimerie et de la Librairie?', o anúncio publicitário da Editora Stock, de Paris, sobre a impressão de Mon bel oranger, título francês de $O$ meu pé de laranja lima. O formato da primeira edição logo dizia ao que vinha em termos da venda de um produto criado para as massas: livro de bolso, 224 páginas, custando 20 Francos, destinado a meninos e meninas de 12 a 16 anos:

Zézé a cinq ou six ans. C'est um petit loustic qui a le diable au corps. Il aime rever, il dialogue avec son oranger et est aussi capable de tours pensables. Sa sensibilité est d'une vivacité exceptionnelle et sa grande aventure, c'est sa haine, vite transformée en amour, pour un chauffeur de camion. Le lecteur s'attache des les premières pages à ce garnement mais aussi au monde dont il est le centre: à son petit frère, Luis; à son grand frère, Totoca; à ses soeurs; à son père sans travail; à sa mère indienne. Mon bel oranger est l'un des plus beaux livres qu'on ait jamais écrits sur l'enfance et son univers. (JOURNAL GÉNÉRAL..., 197I).

Sobre o autor e sua tradutora, informava o anúncio: "Brasileiro. Romancista, ator e diretor de cinema. Prêmio Roquette Pinto, especial 1968, por Mon bel oranger. A tradutora, Alice Raillard". Introduzindo o leitor no universo do personagem Zezé, uma criança brasileira recriada como mestiça - categoria articulada na cultura francesa à literatura popular e à oralidade -, a nota editorial ao mesmo tempo que imprime uma significação ao texto define uma singularidade ao produto oferecido, ambas atribuiçōes são feitas no registro da literatura como "Um dos mais mais belos livros jamais escritos", conferindo um lugar a José Mauro no espaço nacional francês. Sua obra passaria a ser classificada como romance de formaçáo para a juventude, cumprindo o projeto intelectual da editora. Isabelle Nières-Chevrel (NIÈRES-CHEVREL, 2008) observa que as razóes para traduzir podem náo ser imediatamente comerciais, a eleição de títulos pode ser feita como estratégia de renovação em produçôes nacionais

7 Compõem a Bibliographie de la France notificações de todas as publicações recebidas para o serviço de Depósito Legal da Biblioteca Nacional da França.

8 "Zezé tem cinco ou seis anos. É um pequeno sedutor que tem o diabo no corpo. Ele ama sonhar, ele dialoga com sua laranjeira, e é também capaz de passeios bem pensados. Sua sensibilidade é de uma vivacidade excepcional e sua grande aventura, seu ódio, rápido se transforma em amor por um motorista de caminhão. $O$ leitor se liga desde as primeiras páginas a este patife, mas também ao seu mundo onde ele é o centro: a seu irmãozinho Luís, a seu irmão mais velho. Totoca, a suas irmãs, a seu pai sem trabalho, a sua mãe indigena. Mon bel oranger é um dos mais belos liuros jamais escritos sobra a infância e seu universo". 
julgadas consevadoras. Talvez esse tenha sido o caso da Stock nos anos 1970: aproveitar a chance de produzir universais com elementos brasileiros. $\mathrm{Na}$ perspectiva da herança e da constituição de fundos editoriais, para Cécile Térouanne, diretora editorial da Hachette Jeunesse, as traduções de escritores como Vasconcelos e Greta Winberg conseguiram fundar a imagem internacional da coleção (TÉROUANNE, 2008).

Os catálogos editoriais são ferramentas indispensáveis para se conhecer as trocas internacionais. Consultando o catálogo da Stock de 1978, antes de ela ser adquirida pela Hachette, vemos a formação de uma coleção de livros juvenis de bolso chamada Bel oranger com as traduçóes dos romances de Vasconcelos e os de outros escritores estrangeiros. Mon bel oranger e Allons réveiller le soleil, título francês de Vamos aquecer o sol, exercem uma espécie de tropismo sobre outros títulos conhecendo um sucesso absoluto. Encontramos nos volumes listados na Bel oranger, Danny, le champion du monde, de Roald Dahl, Je mappele tigre, da americana Frankcina Glass, ao lado de títulos de Amós Oz, Mark Twan e de Zélia Gattai.

José Mauro entra no mercado francês na companhia justo de Jorge Amado e Zélia Gattai e pelas mãos de Alice Raillard, importante figura de passeur, tradutora do casal e de Darcy Ribeiro, João Ubaldo Ribeiro, Raduan Nassar, entre outros escritores de renome. Raillard viveu por dois anos no Brasil. Décadas depois, quando morava na Espanha foi procurada para traduzir um livro de Jorge Amado, o que lhe valeu um trabalho regular com as ediçóes Stock e com André Bay, diretor literário junto a Marie-Pierre Bay da coleção Bel Oranger. Mas, o laço com o país tropical vinha de sua própria ligação com a cultura latina, declara Raillard em entrevista de 1991 concedida a Françoise Cartano9. A importância de uma oralidade ligada ao popular na elaboração ficcional era um elemento preponderante da cultura brasileira que atraíra a sua atenção como uma experiência do estrangeiro. Na opinião de Raillard, oralidade e popularidade eram transmitidas por escritores diferentes na construçáo comum da mestiçagem.

$\mathrm{Na}$ Argentina e na França, os padróes do gosto talvez não diferissem do uso original no Brasil. A hipótese apresentada de que o universal é

9 Interessante notar que nesta entrevista sobre a prática de tradução de literatura brasileira, a escritora não se refere a José Mauro de Vasconcelos. Para saber mais, ver TransLittérature, 1991. 
uma produção editorial que se desterritorializa nas práticas de tradução foi sendo construída no caminho do objeto da pesquisa. Por conseguinte, a transferência e apropriação intercultural que a caracteriza realizaria a passagem do nacional para o transnacional popular. Ao acompanhar o percurso internacional de $O$ meu pé de laranja lima torna-se evidente o gosto comum por uma escrita espontânea que trazia em si uma estetização das emoçóes. Resta agora indagar as ambivalências na recepção nacional do escritor. Uma crítica guardiã de fronteiras não via com bons olhos sua desenvoltura na escrita. O destino de José Mauro de Vasconcelos assumiu as muitas faces da produção da cultura, sua escrita maleável acabou por definir um gênero editorial voltado para o consumo em sentido invertido, do Brasil para o mundo. Não por acaso, sua obra publicada desde os anos 1940 ganha novo fôlego com $O$ meu pé de laranja lima, somente possível no quadro de mudança favorável à consolidação de uma indústria do livro no Brasil.

\section{José Mauro de Vasconcelos: uma vida em zig-zag}

O meu pé de laranja lima. História de um menino que um dia descobriu a dor foi o livro mais lido no País, em 1969. Suas páginas contam as desventuras de Zézé, um garoto de cinco anos "descobridor de coisas", que mora em Bangu, zona norte do Rio de Janeiro, no final dos anos 1920. Zézé sobrevive aos problemas enfrentados por um pai desempregado e uma mãe operária na fábrica de tecidos. $\mathrm{O}$ aprendizado crudelíssimo do pequeno herói ao lado dos irmãos Luís, Totoca, Lalá, Jandira, Glória, do tio Edmundo e de uma árvore frutífera plantada no quintal de casa - a laranja lima carinhosamente chamada Minguinho e Xuxuruca - acompanha-se de laços atados com personagens adultos de fora do círculo doméstico. Fazem parte do seu universo a gentil D. Cecília, professora do grupo escolar, o português Manuel Valadares com quem aprende o valor do afeto e da amizade, e o baiano Ariovaldo, vendedor ambulante de folhetos de cançóes. Se o Português lhe traz o desencanto da separação e o adoecimento com a experiência da morte, Ariovaldo conduz Zezé ao encontro da cultura popular. Essa figura emblemática da comunicação, nas palavras de Jean-Yves Mollier, realiza na trama a passagem da oralidade ao escrito por meio de uma eficaz metodologia da memorização (MOLLIER, 2009). Seguindo o vozeirão do 
baiano, o garoto movimenta-se com desenvoltura no mundo adulto, antes vivido solitariamente como engraxate nas ruas do bairro. Às terças-feiras, a dupla caminha horas apregoando as letras dos últimos sucessos gravados por Francisco Alves, o Chico Viola, cantando a plenos pulmóes Vicente Celestino, oferecendo o cancioneiro da época em " - folhetos de todos os preços, desde um tostão a quatrocentos réis. Sessenta cantigas novas! Os últimos tangos." (VASCONCELOS, 2017, p. 92).

O meu pé de laranja lima é um tipo de escrita confessional que corresponde à oralidade dos impressos, das canções de rádio e romances sentimentais, mas que faz, acima de tudo, um tributo ao cinema como veículo de massa. O princípio da trama é a construção de uma criança levada, um "diabo arteiro", que não perde a gentileza e a civilidade com a experiência da dor. Mesmo a violência dos castigos sofridos no corpo não o embrutece. Zezé é um exímio jogador de bolinhas de gude e cativo colecionador de figurinhas de artistas norte-americanos. Heróis, cowboys e xerifes, bisões e búfalos, Tom Mix e Fred Thompson, Buck Jones e Richard Talmadge, até Tarzá, o rei das selvas, são evocados por ele nos momentos de sonho e fantasia na brincadeira com o irmão Luís, a fim de equilibrar a rotina miserável. Não é fácil viver sob o mesmo teto com Paulo Vasconcelos, o pai cruel de grandes olhos tristes de tela de cinema, e a resignada Estefânia Pinagé, a mãe índia. Com as esporas de Tom Mix e as pistolas de Fred Thompson, Zezé se mimetiza em índio Apache e a floresta amazônica invisível no quintal vira o oeste selvagem dos filmes norte-americanos. Um dia, o pé de laranja lima dá flores e frutos, tornar-se um pai-árvore, envelhece e é cortado pela passagem do progresso. Em 1969, quando estouraram as vendas do livro, o Ministério da Educação proibiu-o de ser adotado nas escolas, argumentando erros de português no texto.

Os personagens, dizia José Mauro, modelavam a sua autorepresentação de escritor com linguagem simples e regional: "o povo é simples como eu. Não gosta da atitude sofisticada dos escritores em geral. Como já disse, náo tenho nada de escritor, nada da aparência de escritor. Eu me considero dentro do meu jeito de ser. É o meu jeito de ser. Sou eu" (JORNAL DO BRASIL, 1979). Nada mais apropriado a um país pouco alfabetizado. Que fossem corrigir os textos do Guimarães Rosa, defendia-se. 
José Mauro de Vasconcelos nasceu no dia 26 de fevereiro de 1920, no seio de uma família paupérrima, em Bangu, zona norte do Rio de Janeiro. Viveu a infância em Natal, adotado, aos oito anos, por um padrinho rico. A nova família do Rio Grande do Norte o educa com esmero e o incentiva aos treinos de natação no rio Potengi e no mar. Ganhou várias provas de grande distância. Mas, na casa grande do padrinho rico percebia que era um menino "dado", o que talvez tenha deixado marcas no trabalho adulto como uma nostalgia da perda. No curso ginasial lia romances de Graciliano Ramos, Paulo Setúbal e José Lins do Rego. Como o escritor Lima Barreto, conviveu de perto com a loucura. O pai adotivo era diretor de hospício, onde o filho passara a infância lendo livros de psiquiatria e convivendo com os loucos, personagens por vir. Numa entrevista à revista Manchete, em 1973, declarou: "Talvez esse interesse tenha me conduzido à Medicina, curso que abandonei no segundo ano. Rosinha, minha canoa é uma pura psicose maníaco-depressiva." (VASCONCELOS, 1973).

Depois do curso secundário, José Mauro inicia graduações sequenciadas nas faculdades de Medicina, Direito, Desenho e Filosofia, sem, contudo, concluir nenhuma. Em 1952, parte para a Espanha com o auxílio de uma bolsa de estudos em Salamanca. Fica apenas três dias na nova universidade, partindo para Madri, Itália e França, por conta própria. De volta ao Brasil, deixa Natal a bordo de um navio cargueiro e se estabelece no Rio de Janeiro onde trabalha, aos dezesseis anos, como lutador de boxe, depois ganha a vida carregando bananas numa fazenda em Mazomba. A próxima experiência seria como pescador no litoral fluminense, antes de partir para o Recife, onde leciona no ensino primário também para pescadores. Mais tarde, segue em direção ao Centro-Oeste na companhia dos irmãos Villas-Bôas, Orlando, Cláudio e Leonardo. Foi ainda modelo da Escola Nacional de Belas Artes (o Monumento à Juventude, de Bruno Giorgi, é inspirado nele), pintor, desenhista e escultor, bailarino e ator de cinema, teatro e televisão ${ }^{10}$. Tudo isso leva a crer que o modo como organizou sua intervenção no espaço literário, até mesmo a orientação de um projeto criativo, tem a ver com as atividades aparentemente desconexas

10 Os dados biográficos do escritor foram extraidos do ensaio crítico de Luiz Antônio Aguiar na edição comemorativa de 0 meu pé de laranja lima, e do liuro José Mauro de Vasconcelos, o homem e a obra. 
que exerceu nas fronteiras da produção simbólica. Era a sua forma de viver e reivindicar uma independência para a autoria literária seguindo a lógica da produção da cultura audiovisual, embora o requisito fundamental para o reconhecimento duradouro tenha sido o percurso transnacional de sua obra.

José Mauro começa a escrever em 1940. No início de sua carreira, foi aclamado como escritor de literatura regional. Os romances de estreia Banana brava e Barro Blanco são bem recebidos pela crítica especializada. Luís da Câmara Cascudo escreve uma apresentação elogiosa ao Banana brava, livro publicado em 1944 pela Editora Agir. Cascudo traça o retrato do escritor bandeirante que marcha para o oeste em trens de ferro e caminhões, em longas caminhadas para subir as águas escuras do Araguaia, “ (...) caminho do ouro e do diamante, no reino bruto dos-que-se-atiram-primeiro" (CASCUDO, 1944, p. 2). Compara-o ao norte-americano Jack London, "Vasconcelos dirá: eu sou a grande aventura". O segundo romance, Barro Blanco, ambientado nas salinas do Rio Grande do Norte, é publicado pelo Instituto Progresso Editorial de São Paulo, em 1948. O suplemento $O$ Mundo dos livros da revista $O$ Cruzeiro, de 30 de outubro do mesmo ano, também o compara a Jack London, “(...) pelo espírito de aventura e compaixão humana de suas histórias", e conclui: Barro Blanco é um livro brasileiro (O CRUZEIRO, 1949).

Em entrevista concedida a Audálio Dantas, jornalista da revista Realidade ${ }^{\prime \prime}$, José Mauro conta que de sua primeira viagem à selva, abrindo mato a peito, morando com os índios e se aventurando no garimpo, nasceu o Banana brava, livro-experiência que lhe "custou a perna direita quebrada em três lugares". Na volta da aventura, subindo o rio Tocantins, trazia o livro pronto na cabeça, escreveu-o em vinte e sete dias. Chegando a São Paulo, onde residia de favor na casa de uma tia, resolveu cuidar da perna paralisada. Viajou ao Rio de Janeiro a fim de se tratar em um hospital de indigentes, lá conheceu um frade dominicano que leu os originais do livro os levou para a Editora Agir. A sua estreia, na editora carioca, foi junto a de Guimarães Rosa, Banana brava e Sagarana viram os dois a mesma luz da publicidade. Vale notar que o destino de Barro Blanco foi mais decisivo

II Revista Realidade, 1979 
na sua carreira de bandeirante moderno. O novo livro denunciava o drama da exploração dos trabalhadores nas salinas do Rio Grande do Norte por grandes empresas instaladas na regiáo, como a Matarazzo. Logo fez sucesso de crítica e público. Um ilustrado leitor de Sáo Paulo, Ciccillo Matarazzo, sentiu-se especialmente tocado pela narrativa, quis conhecer o jovem autor, José Mauro de Vasconcelos. Autor e leitor firmam uma amizade longeva. O criador da Bienal Internacional do Livro e do Museu de Arte Moderna de São Paulo, fundador da Companhia Cinematográfica Vera Cruz, entre outros empreendimentos culturais, pagou quase todas as cirurgias da perna do escritor, além de presenteá-lo com máquinas de escrever, "Ganhei quatorze máquinas de escrever dele. Quando eu acabava de escrever um livro e não tinha dinheiro para comer, vendia a máquina, e o Ciccillo me dava outra". Anos depois, o amigo mecenas fingiu-se de bravo e disparou: " - deixa de ser besta. Você é mais rico do que eu".

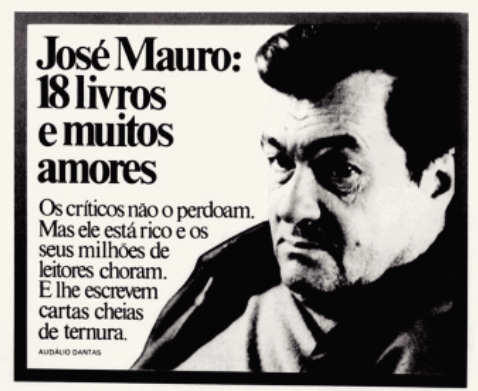

Figura 3 - Abertura da matéria "José Mauro: 18 livros e muitos amores”, da Revista Realidade, outubro de 1979

José Mauro soube valorizar o trânsito no universo de uma burguesia bem educada da high society paulistana. Aparecia com frequência nas colunas sociais de Tavares de Miranda, da revista $O$ Cruzeiro $^{12}$. Suas fotografias celebrando amizades na alta roda de Ciccillo Matarazzo, junto a Adelino e Yan de Almeida Prado, Marcelino de Carvalho, Pierpaolo Gembriani, Olinto Moura e o repórter, em almoços regados a vinho e a cachaça, dizem

12 Para saber mais, ver O Cruzeiro, 1973. 
muito sobre o modo como suas escolhas pessoais se ligavam às profissionais. Soube igualmente valorizar as operaçôes de uma dedicatória. Em $O$ meu pé de laranja lima faz uma oferta a Ciccillo, com a advertência "para os vivos" na edição original, e "para os que nunca morreram”, nas ediçóes posteriores à morte do amigo, antes de mencionar os parentes que já se foram deixando saudades. A primeira edição de Rosinha, minha canoa é exclusivamente dedicada ao "Ciccilão", assim como outros livros. Tímido e arredio, não agradava a José Mauro a participação no que entendia como coletivo da literatura. A alta literatura ligada a uma sociabilidade específica mimetizava as elites aristocratas e lhe soava artificial, razão pela qual elegia seus interlocutores entre os mediadores de fora dos mundo estritamente das letras. Identificava-se mais ao modelo do escritor na tradição dos contadores de história. É justo nessa linhagem que pretendia inscrever a sua autoria e ver-se representado como artista. Para ele, "O erro do escritor brasileiro é fazer mais poses do que escrever: James Joyce, Franz Kafka, Proust, Graciliano, Jorge Amado e Lima Barreto, são também contadores de história como eu". Talvez por sua visão negativa da sociabilidade literária tenha incentivado a disputa entre a crítica especializada e seu público. Em várias entrevistas, declarara que as opiniōes de críticos universitários não importavam tanto como a dos agentes do mundo do livro, comerciantes, mecenas e editores. $\mathrm{O}$ percurso de publicação do autor, no entanto, não poderia ser tomado isoladamente, fora das redes de conexóes e atuaçóes pelas quais se movimentava. Incluindo todas as modalidades de diálogo com suas tradutoras, Haydée Barroso e Alice Raillard, que ajudaram a inscrever sua obra juvenil no cânone universal.

Em março de 1949, No mundo dos livros publica uma resenha de Geraldo de Freitas intitulada $O$ fascínio dos sertóes, inserindo-o na mesma safra do escritor Herberto Sales, de $O$ cascalho, que conta a vida simples e as lutas de homens heróicos no garimpo. $\mathrm{Na}$ apreciação positiva do crítico o mesmo acontece com Longe da Terra, de José Mauro. E segue derramando elogios à linguagem simples do autor, ao estilo vibrante e plástico com que narra a vida dos índios Carajás, "Longe da terra nos revela um grande pedaço do Brasil, duro, trágico e maravilhoso e confirma as qualidades de um novo escritor brasileiro, em torno de cujo nome já se formou a auréola 
de ser um grande bandeirante moderno, apaixonado pelos sertóes e pela gente simples, boa e corajosa de nossa terra”.

José Mauro de Vasconcelos também participou do cinema nacional. Em 1956, seu romance Arara vermelha é adaptado e distrubuído pela Columbia Pictures do Brasil, com Tom Payne na direção e o elenco formado por Anselmo Duarte, Odete Lara, Milton Ribeiro, Helio Souto e Ricardo Campos. Em 1961, o escritor estreia como ator em Mulheres e milhóes junto a nomes famosos, como Odete Lara, Glauce Rocha e Jece Valadáo, e ganha o prêmio Saci de melhor ator. Em 1962, atua em $A$ ilha, ao lado de Eva Vilma, Elizabeth Hartman, Liris Castelani e Laura Verney, sob a direção de Walter Hugo Khoury.

A desavença com a crítica e o sistema de classificação das obras ganha força com o sucesso transnacional de $O$ meu pé de laranja lima. O destino do romance foi além da edição impressa. Adaptado para o cinema entrou no teatro e na novela de televisáo da Tupi em 1970 (escrita por Ivanir Ribeiro e dirigida por Carlos Zara). Tudo indica que a perenidade do livro dependeria da conservação da imagem, sendo José Mauro um telenovelista da escrita. É ilustrativo o anúncio publicado no Caderno B do Jornal do Brasil ${ }^{13}$ em que a Editora Melhoramentos articula o produto livro ao filme de cinema: "um filme pra ver (e rir e chorar e enternecer), um livro pra ter (e reler e guardar e reler)". Rua descalça, outro romance de José Mauro, também foi adaptado ao cinema, em 1971, com direção de J. B, Tanko. Dedicado ao público infantil, concorria com uma produçáo de Walt Disney, Em busca da aventura. No mesmo ano vão para o cinema As confissóes do Frei Abóbora, com a direção e roteiro de Brás Chediak, com Tarcisio Meira, Emiliano Queirós e Norma Benguel no elenco.

Afinal, a quem interessaria o sucesso de seus livros no exterior? $\mathrm{O}$ trabalho dos tradutores profissionais e a boa recepção em outros países de $O$ meu pé de laranja lima concentrou a crítica especializada brasileira no debate se José Mauro pertencia ou não à literatura. No romance sentimental que dava a palavra às árvores, ponderava Eduardo Portella, José Mauro

13 As fontes periódicas, como os jornais e revistas, oferecem variadas oportunidades de análise, descortinam relações e trocas literárias. Por isso, são largamente utilizadas neste artigo. 
construía a metáfora cordial de uma rejeição. Cabe perguntar: afinal, de qual rejeição tratava o crítico? O rebaixamento de posição e deslocamento para as margens aliados à trajetória transnacional de sucesso redesenhava o caminho da conquista de autonomia no campo nacional. $\mathrm{O}$ desgosto de Eduardo Portella sobre o best-seller foi publicado na revista Manchete, um ano após a sua publicação:

O livro de José Mauro de Vasconcelos é antes de tudo literatura ingênua, por vezes sentimentalóide, frequentemente melodramática. Desenvolvendo-se sob a forma de uma narrativa memorialística, O meu pé de laranja lima conta as peripécias de uma criança pobre "um meninozinho que um dia descobriu a dor". A infância reprimida tem sido o salto patético da ética ocidental. Mas não se trata aqui de um corte vertical sobre o drama humano, onde um tema tópico esconde um problema social, no caso ingenuamente aflorado. Não resta dúvida de que $\mathrm{O}$ meu pé de laranja lima, essa metáfora cordial de uma rejeição, é uma provocação constante às emoções fáceis. E como a civilização do lazer consome desesperadamente comprimidos de evasão, ele é o maior best-seller do ano. (MANCHETE, 1969).

Noutra ocasiáo, o crítico Gilberto Medonça Teles' ${ }^{14}$, que o conheceu numa viagem de férias pelo Araguaia, o perguntou se considerava-se parte do que naquele momento era a literatura brasileira e se pensava corresponder sua obra à de Guimarães Rosa e Clarice Lispector. Mas José Mauro, afirma o crítico, parecia não se importar, interessava-lhe contar histórias (JORNAL DO BRASIL, 1979). A crítica, então, deveria repensá-lo sob o ponto de vista da estética da recepção e partir do interesse do leitor brasileiro e estrangeiro, pondera Mendonça Teles, manifestando a sua simpatia pelo escritor. José Paulo Paes (PAES, 1990), por sua vez, sugere um levantamento e avaliação de nossa literatura brasileira do entretenimento, em cujo panteão constam as figuras de Maria José Durpré e José Mauro de Vasconcelos. Ainda que José Mauro não tenha operado qualquer revolução simbólica e os gêneros que praticou tenham sido modelaçóes da indústria cultural, Paes adverte: "a agressividade com que certos críticos se voltaram contra ele, julgando-lhe o desempenho unicamente em termos de estética literária, em vez de analisá-lo pelo prisma da sociologia do gosto e do consumo, mostra a miopia de nossa crítica para questóes que

14 Para saber mais, ver Jornal do Brasil, 1979. 
fujam ao quadro da literatura erudita" (PAES, 1990, p. 34). A trajetória internacional do "fenômeno" objeto deste artigo - combatido, ignorado ou elogiado - levou a crítica brasileira a reconsiderar a classificação e apreciaçáo da literatura, sobretudo a infantojuvenil, sob o ponto de vista do leitor. O que não é pouca coisa.

\section{Uma nota de inconclusão}

Os trabalhos da tradução examinados neste artigo certamente atribuíram novos e inusitados sentidos aos textos de José Mauro de Vasconcelos. Procuramos mostrar que na lógica das escolhas, as afinidades de gosto de linhas editoriais e títulos dependeram das relaçóes entre os espaços nacionais brasileiro, francês e argentino. Uma obra quando circula de um país ou continente a outro, observa Pierre Bourdieu (2009), leva consigo o campo da sua produção e circulação. Ou melhor, leva a porção do campo na qual se insere e que interessa aos intermediadores: a da produção canônica ou a da produção popular massiva. As transferências entre espaços nacionais se fazem por meio de uma série de operaçóes entre agentes sociais, a exemplo da seleção do que merece ou não ser traduzido e publicado e dos que reúnem competência e legitimidade para verter os textos de uma tradição linguística a outra. Tais operaçóes de leitura estáo baseadas em categorias de percepção e problemáticas próprias a espaços específicos, como o de língua hispano-americana e o de língua francesa. As tramas de imposição simbólica ditadas pelas altas posiçóes de escritores e editoras globalmente situadas, no entanto, vêm demonstrando não reconhecer fronteiras, podendo tornar-se um dos pontos de convergência entre esferas nacionais assimétricas e um dos lineamentos do que se poderia chamar espaços transnacionais de circulação literária. No final das contas o que importa é que a décima edição de Mi planta de naranja-lima, no ano de 1978, ampliou os canais de circulação da literatura juvenil brasileira. A tiragem de 100.000 exemplares, só na cidade de Buenos Aires, e as representaçóes da El Ateneo Editorial nas cidades de Lima, Caracas, México, Barcelona, Madri e Bogotá teceram redes de interdependências que necessitam ser recompostas por uma sociologia interessada na transnacionalização da cultura. 


\section{Referências}

AGUIAR, L. A. A literatura de O meu pé de Laranja Lima. In: VASCONCELOS, J. M. O meu pé de laranja lima. Sáo Paulo: Melhoramentos, 2017.

BARROSO, H. M. J. Vida y saga de Jose Mauro de Vasconcelos. Buenos Aires: Libreria El Ateneo Editorial, 1978.

BOURDIEU, P. Les conditions sociales de la circulation internationale des idées. In: Sapiro, G. L'espace intellectuel en Europe. De la formation des États-nations à la mondialisation XIXe-XXIe siècle. Paris: La Découvert, 2009.

CASCUDO, L. C. Apresentação do livro de José Mauro de Vasconcelos. In: Banana Brava. Rio de Janeiro: Melhoramentos, 1944. (Coleção Centenário de Luís da Câmara Cascudo).

CHARTIER, R. A máo do autor e a mente do editor. São Paulo: UNESP, 2014.ELIAS, N. O processo civilizador. Uma história dos costumes. Rio de Janeiro: Zahar, 2011.

FREITAS, Geraldo. O fascínio dos sertôes. O Cruzeiro. 26 mar.1949. Disponível em: <http:// memoria.bn.br/DocReader/DocReader.aspx?bib=003581\&PagFis=63603\&Pesq=Jos\%C3 \%A9\%20Mauro\%20de\%20Vasconcelos>. Acesso em: 20 dez. 2017.

HALLEWELL, L. O livro no Brasil. Sua história. São Paulo: EDUSP, 2012.

JORNAL DO BRASIL. Nunca se editou tanto no país e jamais se leu como agora. 30 de novembro de 1971. Disponível em:

http://memoria.bn.br/DocReader/DocReader.aspx?bib=030015_09\&PagFis=4443\&Pesq=jos\%C 3\%A9\%20mauro\%20de\%20vasconcelos Acesso em: 10 jan. 2018.

O Escritor deve se dar por satisfeito quando o público o descobre. Um fenômeno chamado José Mauro de Vasconcelos. 21 out. 1979. Disponível em: <http://memoria.bn.br/ DocReader/DocReader.aspx?bib=030015_09\&PagFis=207168\&Pesq=EDITORA\%2>. Acesso em: 21 dez. 2017.

JOURNAL GÉNÉRAL DE L'IMPRIMERIE ET DE LA LIBRAIRIE. Bibliographie de la France. 17 nov. 1971. Disponível em: <http://gallica.bnf.fr/ark:/12148/bpt6k6101161s/f112.image. r=José\%20Mauro\%20de\%20Vasconcelos?>. Acesso em: 20 fev. 2018.

LEÃO, A. B. Fazer do velho uma novidade. As reinvençóes dos best-sellers juvenis. Caderno CRH, Salvador, vol. 29, n. 78. set./dez. 2016.

LINDOSO, Felipe. José Mauro de Vasconcelos: o subestimado muito traduzido. Publishnews, 4 mar. 2015. Disponível em: <http://www.publishnews.com.br/materias/2015/03/04/80885-josemauro-de-vasconcelos-o-subestimado-muito-traduzido $>$. Acesso em: $1^{\circ}$ jan. 2018.

MARTINS, W. História da inteligência brasileira. vol. VII. São Paulo: Cultrix, 1979.

MAZIEIRO. M. D. S. Arnaldo de Oliveira Barreto e a Biblioteca Infantil Melhoramentos (1915-1925): histórias de ternura para mãos pequeninas. Tese (Doutorado em Educação) Faculdade de Educação. Unicamp.Campinas, 2015. 
MOLLIER, J. Y. O camelô. Figura emblemática da comunicação. São Paulo: EDUSP, 2009.

L'émergence de la culture de masse dans le monde. In: MOLLIER, Jean-Yves, SIRINELLI, Jean-François, VALLOTTON, François (Org.). Culture de masse et culture médiatique en Europe et dans les Amériques. 1860-1940. Paris: PUF, 2006.

NIÉRES-CHEVEL. I. Littérature de jeunesse et traduction: pour une mise en perspective historique. In: Traduire les livres pour la jeunesse: enjeux et spécificités. Paris: Hachette, Bibliothèque National de France/Centre national de la littèrature pour la jeunesse, 2008.

O CRUZEIRO. Casa dos Llerena recebe, na GB. 15 out. 1976. Disponível em: <http://memoria. bn.br/DocReader/DocReader.aspx?bib=003581 \&PagFis $=187080 \&$ Pesq=Jos\%C3\%A9\%20 Mauro\%20de\%20Vasconcelos>. Acesso em: $21 \mathrm{dez} .2017$.

Escolha aquí entre os melhores livros do ano. 1946. Disponível em: $<$ http://memoria. bn.br/DocReader/docreader.aspx?bib=003581 \&pesq=Jos\%C3\%A9\%20Mauro\%20de\%20 Vasconcelos>. Acesso em: 20 dez. 2017.

ORTIZ, R. A moderna tradiçáo brasileia. Cultura brasileira e indústria cultural. São Paulo: Editora Brasiliense, 1994.

PAES, J. P. A aventura literária. Ensaios sobre ficçáo e ficçóes. São Paulo: Companhia das Letras, 1990.

Armazém Literário. Ensaios. São Paulo: Companhia das Letras, 2008.

REVISTA REALIDADE. José Mauro: 18 livros e muitos amores. São Paulo: Editora Abril, out. 1979 .

SOARES, G. P. Semear Horizontes. Uma história da formaçáo de leitores na Argentina e no Brasil, 1915-1954. Belo Horizonte: Editora UFMG, 2007.

SORÁ, G. Traducir el Brasil. Una antropología de la circulación internacional de ideas. Buenos Aires: Libros del Zorzal, 2003.

Brasilianas: José Olympio e a gênese do mercado editorial brasileiro. São Paulo: EDUSP, 2010.

TÉROUANNE, C. Politique éditoriales et traductions. In: Traduire les livres pour la jeunesse: enjeux et spécificités. Paris: Hachette, Bibliothèque National de France/Centre national de la littèrature pour la jeunesse, 2008.

TETTAMANZI, R. Les écrivains français et le Brésil. Paris: Editions L’Harmattan, 2004.

TORRESSINI, E. R. Editora Globo. Uma aventura editorial nos anos 30 e 40. São Paulo: EDUSP, COM-ARTE- Editora da UFRGS, 1999.

TRANSLITTERATURE. Entretian D'Alice Raillard. [1991]. Disponível em: <http://www. translitterature.fr/media/article_643.pdf>. Acesso em: 21 dez. 2017. 
VASCONCELOS, J. M. O meu pé de laranja lima. São Paulo: Melhoramentos, 2017. Mol bel oranger. Paris: Éditions Stock, 1971.

VERISSIMO, E. Um certo Henrique Bertaso. Pequeno retrato em que o pintor também aparece. São Paulo: Companhia das Letras, 2005.

\section{José Mauro de Vasconcelos: The interpreter and translations of Brazil}

\section{Abstract}

This article addresses the life and work of the writer José Mauro de Vasconcelos. It has the triple objective of discussing comparatively the nationalization and internationalization logics of the youth literature production, the shifts and submissions throughout the author's trajectory and the correlation between his translated work and the expectation of Brazilian, French and Spanish-American readers. Therefore, the contingencies and choices apparently disconnected in José Mauro's profession, an intellectual who would never be enshrined by established authors, deal with the antagonistic centers which interact in the literary space and guide the book industry through the twentieth century: between passeurs and national borders guardians, between traditional literature made erudite and foreign literature made massive popular.

Keywords: José Mauro de Vasconcelos. Youth literature industry. Literary translation. Massive popular literature. Popular national and transnational.

Recebido em: 28/05/2018

Aceito em: 05/07/2018 